192 Tropelías. Revista de Teoría de la Literatura y Literatura Comparada, número extraordinario 1 (2017) Nicolás Miñambres Sánchez

\title{
RECUERDOS DE LOS AÑOS OCHENTA. HUBERTO PÉREZ DE LA OSSA
}

\section{Nicolás MIÑAMBRES SÁNCHEZ}

$Q$ uerido José Enrique:

Yo fui un hombre afortunado. Surgió mi amistad contigo y, casi al mismo tiempo, el conocimiento de un autor de teatro, Huberto Pérez de la Ossa, ahora tal vez fuera de los caminos oficiales. Su obra cambió mi opinión: en casa de mi cuñado, Pedro Redondo Pérez de la Ossa, «el tío Huberto», era su tío abuelo. Conservaban además, todo el fondo bibliográfico: originales de novelas, obras de teatro, libros de poemas. Todo un mundo. Para afianzar mis hallazgos recurrí a mi querido maestro y amigo Ricardo Senabre. Hablé con él y su juicio fue rotundo: Huberto era un tema admirable para una tesis. Por qué no la hice... no lo sé.

En aquel momento se fortaleció nuestra amistad. Para mí siempre y para ti desde entonces, Ricardo Senabre, fue uno de nuestros faros intelectuales y humanos. Desgraciadamente, la vida no fue elegante con él y hace pocos años nos dejó. Esté donde esté que su alma recoja el eco de mis palabras. $Y$ que todo esto sea in memoriam Ricardo Senabre.

He vuelto al mundo de Huberto Pérez de la Ossa. He rebuscado con interés entre sus abundantes papeles y he descubierto documentos interesantes. Ten en cuenta que Huberto, que padeció los horrores de la Guerra Civil, posteriormente tuvo la fortuna de asentarse en el mundo del teatro, ocupando cargos importantes.

Quiero exponer mi trabajo con sencillez, en tono estrictamente divulgativo. Sin notas a pie de página, ni bibliografía, salvo la referencia a la obra del Ministerio de Cultura, VVAA, (1993) HISTORIA DE LOS TEATROS NACIONALES 1939-1962, con múltiples referencias a Huberto Pérez de la Ossa.

Estos folios son exclusivamente una recuperación de materiales seguramente olvidados. Estoy sólo haciendo hemeroteca documental. De ahí la posible aridez de mi trabajo y su falta de conclusiónes. Y...quién sabe: a lo mejor algunos textos están publicados, pero no estos autógrafos de Huberto Pérez de la Ossa.

\section{Ecos literarios de Huberto Pérez de la Ossa}

Nacido en Albacete en 1897 y fallecido en Salamanca en 1983, su vida incluye una obra variada (novelas, obras de teatro, obras de poesía, traducciones, artículos periodísticos...) pero, por encima de ello, se observa, aparte de una incipiente vocación médica, una auténtica veneración por el teatro, perceptible en todos los documentos.

Disponemos de tres folios de mecanografía anticuada donde Huberto Pérez de la Ossa describe sus recuerdos infantiles, con cierto sabor por la poesía, para La Estafeta Literaria: 


\begin{abstract}
Cuando yo nací, las señoras bien educadas leían a los poetas. Yo leía al mismo tiempo que los cuentos de hadas, los libros de versos que andaban por el costurero de mi madre. Quise hacer versos también. Mi padre me enseñó a contar las sílabas, me explicó lo que era la rima. Fue entonces un ejerció inocente que me proporcionaba un gozo maravilloso.
\end{abstract}

En este comienzo y con algunos estudios de periodismo, escribe sus primeros cuentos, para llegar a El ancla de Jasón (1921). Poco después aparecería una de sus obras más prestigiosas, Polifonías (1922)

\title{
Narrativa
}

Dado que el trabajo pretende exclusivamente una mínima exhumación de un rico archivo documental, no entraré en el análisis de la obra. Me limitaré a recordar sus títulos principales.

El ancla de Jasón. Biblioteca Patria, Madrid, 1921, obra laureada con el premio Juana y Rosa Quintana. La lámpara del dolor, 1923. Papeles viejos, Biblioteca Patria, Madrid, 1923. El opio del ensueño, Renacimiento, Madrid, 1924. La Santa Duquesa, Renacimiento, Madrid, 1924 (Premio Nacional de Literatura). La libertad y Claudio: cromo de motín sobre fondo barcelonés, La Novela Mundial, Madrid, 1926. Veletas: libro de historias extraordinarias, Virtus, Buenos Aires, 1926. La casa de los masones. Mundo Latino, Madrid, 1927. Obreros, zánganos y reinas, Mundo Latino, Madrid, 1928. Roca viva, Editorial Atlántida, Madrid, 1930. Los amigos de Claudio, La Novela Mundial, Madrid, 1931.María Fernanda, Londres, 1931, Boston, 1931. La traducción de esta última es del hispanista E. Allison Peers. El aprendiz de ángel 1935.

\section{Teatro}

En el kilómetro 13. 1945. Adaptación de la Celestina de Fernando de Rojas, junto a Luis Escobar. Imprenta de Arges, 1959.

\section{Lírica}

Polifonías. Sones de órgano. En el clave. Esquilas. Música interior. Poesía (1915-1922) Mundo Latino, Madrid, 1922.

\section{Biografías}

Teresa de Jesús, Editorial Colón, Madrid, 1930. Danton, Editorial Colón, Madrid, 1930. Orellana y la jornada del Amazonas, Editorial Colón, Madrid, 1935. Pedro de Mendoza y la fundación de Buenos Aires, Biblioteca Pax, Madrid, 1936. Almagro y La Epopeya de Los Andes. Descubrimiento de Chile 1536. Biblioteca Pax, Madrid, 1936.

Indudablemente, en esta panorámica está ausente la bibliografía especializada, innecesaria en una semblanza como es este breve trabajo. Lo escrito es meramente indicativo, sencillo, respecto a una personalidad que desborda todo lo que pudiera escribirse sobre ellal. Esta condición de literatura 
personal, nos hace pensar en que no existe copia de los documentos. De existir, no sería menoscabo para esta aproximación.

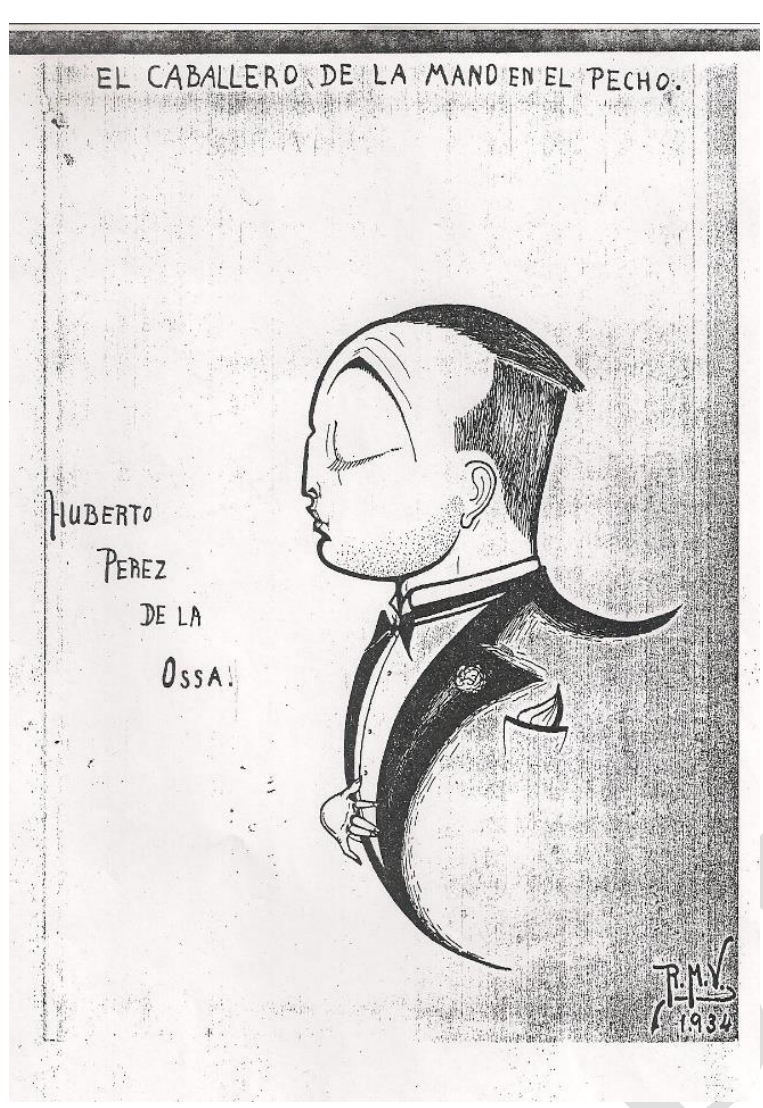

\section{Lo humano. La correspondencia}

Existe un hecho histórico que condiciona, como a tantos españoles, la personalidad de Huberto (de quien limitaremos la denominación a su nombre de pila, sin sus apellidos correspondientes), la Guerra Civil. Sufre las calamidades del ejército rojo, pero consigue ser liberado en Barcelona, y se convierte en «agregado al Servicio de Recuperación del Patrimonio Artístico Nacional». Más tarde es nombrado Subcomisario del Teatro Nacional y Secretario de la Real Escuela de Arte Dramático, «con la gratificación anual de cinco mil pesetas para gastos de representación». Es el momento en que establecerá relaciones diversas con multitud de intelectuales y artistas.

Una primera muestra epistolar, inclasificable por la falta de documentos informativos, es su posesión del corpus al que podemos denominar Cartas a Eduardo de la Iglesia, de quien hemos sido incapaces de localizar rasgos de su personalidad, aunque sí su dirección: C/ Hermosilla 30, Madrid. Se trata de más de cincuenta cartas, de tres o cuatro folios muchas de ellas, escritas a mano por Dolores, que se las envía a Eduardo a través de enlaces diversos.

La colección epistolar es un misterio. Dolores se manifiesta con una curiosa caligrafía (cambiante de forma extrema de unas cartas a otras, dependiendo seguramente del estado de ánimo) siempre identificable. Escribe como una mujer apasionada, con un hondo sentido del amor. Es imposible mostrar más intensamente en unas líneas quién es Eduardo. Sabemos también que la madre de Dolores llega desde América y será recogida por las hermanas de Dolores en Francia. Y hallamos conservada una tarjeta del hotel Majestic de Sevilla, uno de los grandes hoteles de la España del momento. No existen más referencias.

Dentro del epistolario hay que referirse a las cartas de Concha Espina, un documento excepcional del que hace años di cuenta en el suplemento literario «Filandón», del Diario de León.

Aunque sin orden (u orden imposible, dada la variedad de autores, la extensión de las cartas, la diversidad de temas...) referiré los principales destinatarios de los documentos epistolares. Por los años treinta, se conservan las comunicaciones de Mario Verdaguer, repletas siempre de un contenido original. De los mismos años son las siete entregas de Nicolás González Ruiz, desde el periódico El 
Debate. O de Manolo Ballesteros, o Guillermo Díaz Plaja. La lista resulta casi interminable: Emilio Miró, Victorio Macho, A. Palacios Valdés (con su dirección en $\mathrm{C} /$ Lista 5 Madrid), Eduardo Marquina... Incluso tenemos una caricatura a plumilla firmada por Buero Vallejo. Abundan igualmente las cartas de Luis Escobar, comisario de teatro y gran amigo suyo, de Víctor Ruiz de Iriarte, del Marqués de Luca de Tena o de Fernando Díaz de Mendoza. Sin olvidar otros documentos, cartas y escritos teatrales de Rafael Martínez Romarate, conservadas en su Teatro Fantasio, fuente de tantas sorpresas.

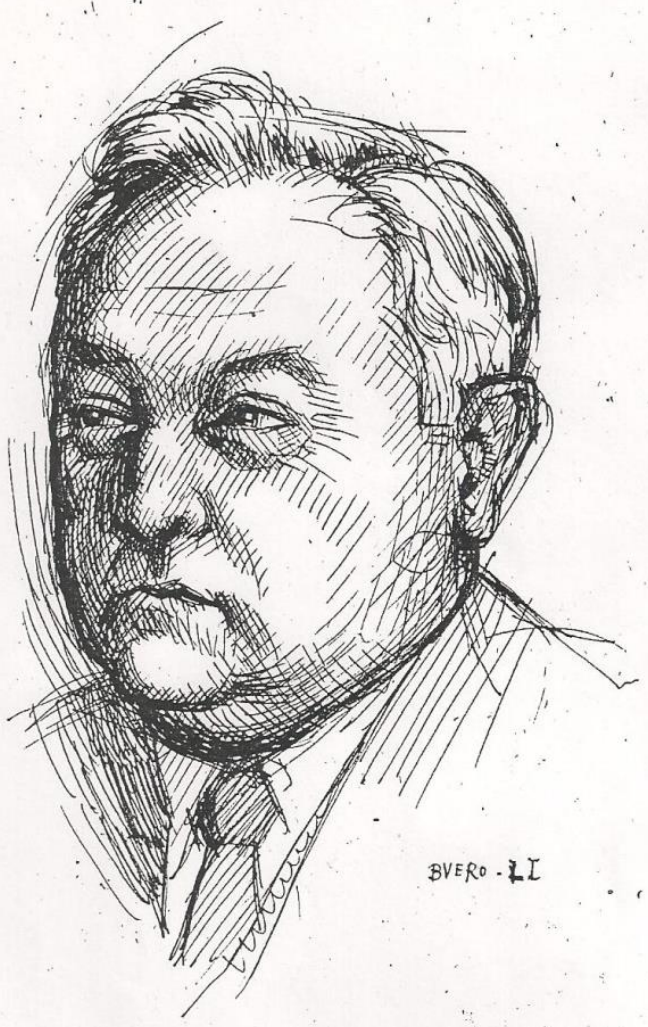

Lo profesional. Borradores y proyectos

Su liberación del ejército rojo con la toma de Barcelona y el acceso a ciertos cargos permiten a Huberto la elaboración de valiosos documentos autógrafos, curiosamente escritos a lápiz o mecanografiados, que consideramos de gran valor. Presentamos una de las muestras más llamativas: $\mathrm{Su}$ caligrafía, líneas, nombres, redacción, actividades, réplicas, contrarréplicas, direcciones... lo convierten en un precioso documento polimórfico, de gran valor teatral, sociológico, literario y humano.

El documento que presentamos en primer lugar es un borrador, sin título ni fecha desgraciadamente. Se inicia con un «Marqués de Lozoya» en la primera línea y ocupa seis cuartillas, dos escritas con tinta 
196 Tropelías. Revista de Teoría de la Literatura y Literatura Comparada, número extraordinario 1 (2017) Nicolás Miñambres Sánchez

y cuatro con lápiz. Su lectura da una idea de lo efímero de lo escrito, pero también de lo interesante de
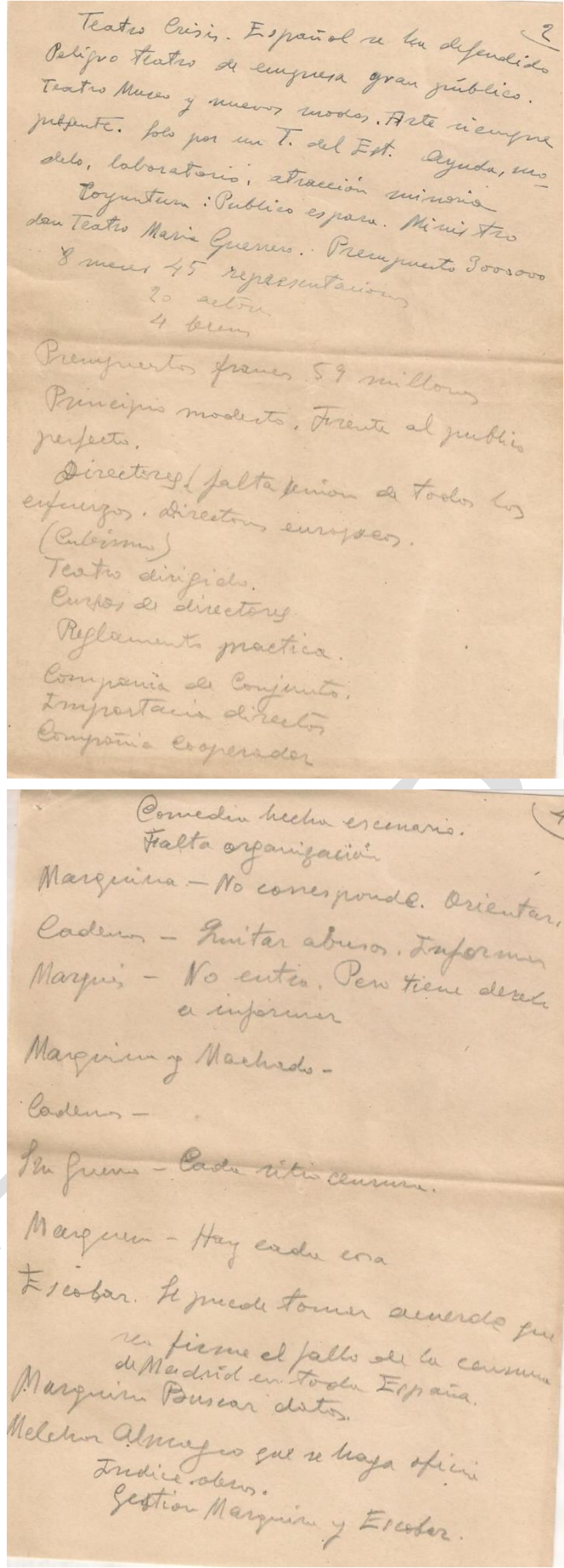
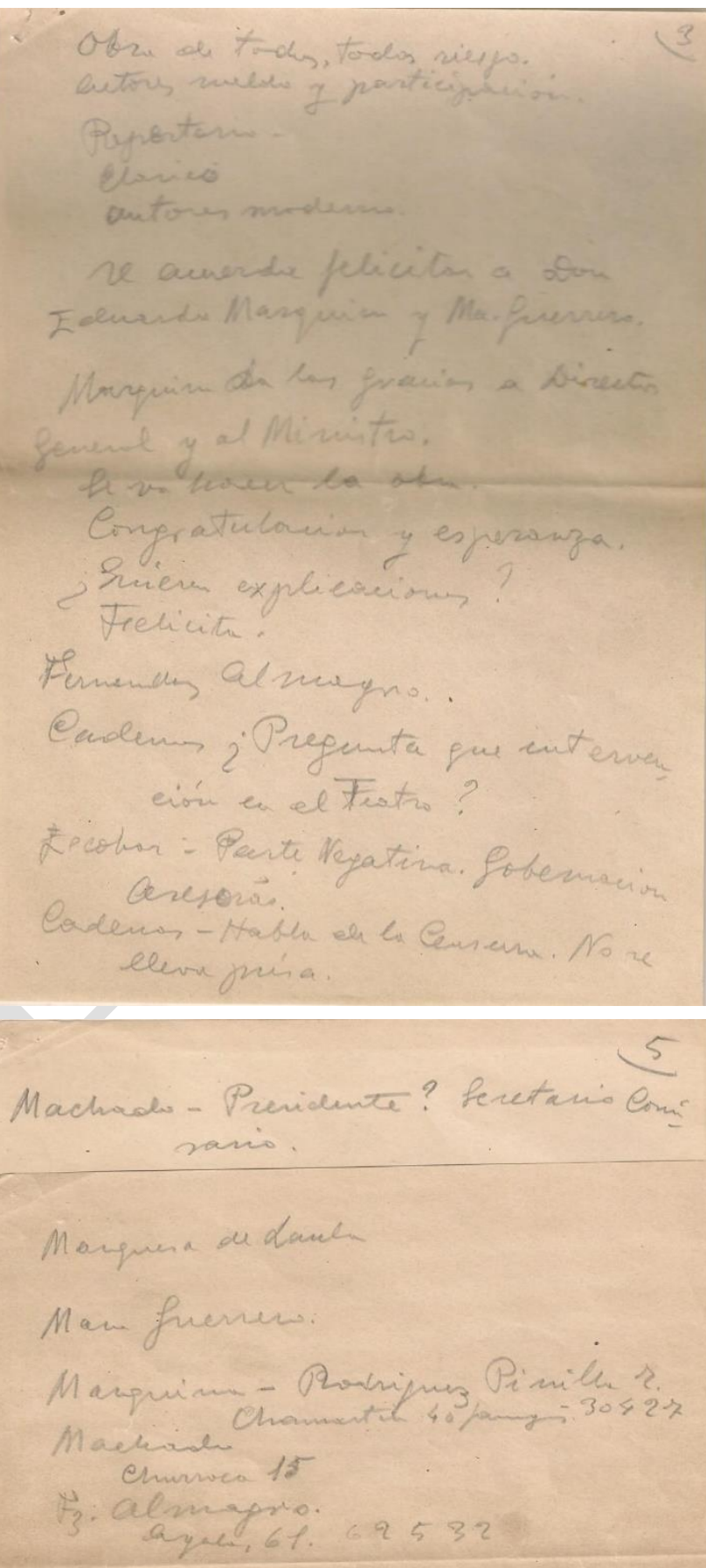

Morem Tonob

Olundis de torn
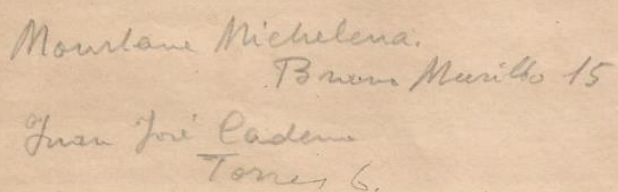

Anaryo losta $14-7 \% 214$ 
su contenido. La relación onomástica y sus confesiones pueden ser motivo y pretexto de un informe sociológico y literario del momento. Es uno de los primeros documentos conservados y cargado de noticias, sucesos y nombres, aunque, como se comprueba, presenta las limitaciones de un borrador improvisado, telegráfico casi. Son, a fin de cuentas, poco más que notas tomadas al volapié, que se hacen más ininteligibles a medida que avanza el texto, que finaliza con una mínima relación de direcciones y algún número de teléfono.

\section{Literatura anónima}

En segundo lugar deben recordarse una serie de romances, sin autor, de cierto valor literario, aunque sus versos sean sólo una visión mítica de la Guerra Civil. Los tres cuadernillos van precedidos como lema de unos versos de José Santos Chocano. Se conservan en tres cuadernos tamaño cuartilla. Hay que advertir que el tono, a pesar de su carácter bélico, es notable. No hay que olvidar que se trata de composiciones anónimas, tituladas en mayúsculas en el texto.

- $1^{\text {a }}$ Serie: Romances de guerra y conquista. (Motivos: Real Alzamiento). Guerra. Preludios. Un Caudillo. África. Cádiz (Jaén). El Santuario de la Ermita de La Cabeza. Granada. Córdoba. Sevilla. (Seis páginas).

- $\quad 2^{a}$ Serie: Romances de guerra y de conquista (Motivos: El Alcázar de Toledo. El Cuartel de Simancas. Los sufrimientos de Oviedo (Seis páginas)

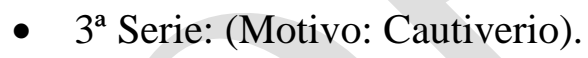

Junto a ellos conserva también el curioso romance anónimo, extenso, Montserrat, de ambiente catalán. Narra de forma humorística las vicisitudes de un viajero que va en el tren hacia Barcelona. Es un divertido juguete teatral con dibujos del humorista Húpe, que tal vez exigiera un análisis detallado.

Precisamente de esta especie de prehistoria literaria conserva-mos otros poemas anónimos, grapados, autógrafos, de contenido per-sonal, que responden a los siguientes títulos, lugar de composición y fecha, según han quedado agrupados. A saber: «Amor frío». Sevilla, 1912. «La voz eterna». Córdoba, 1914. «Vino de Montilla». Sevilla, 1915. «En el triclinio»Valencia, 1919. «In sensu». Málaga, 1913 «Álvaro Leone». Valencia, 1918. «Francisco Galán». Valencia, 1918. «El fauno enclaustrado», Madrid, 1916. «El lecho de Dalila», Valencia, 1918. «Laura y Rosario», Sevilla 1913. «Renacimiento», un poema largo, fechado en Madrid en 1916.

\section{Proyectos marginales de interés}

En tono preciso y oficial se ofrece, desgraciadamente sin fecha, un trabajo de dos folios intensos tipográficamente, con el título genérico de Dirección General de Bellas Artes, también en mayúsculas 
en el original, muy interesante para los estudios del teatro de posguerra. Ofrecemos en minúsculas también el original de la introducción:

$1^{\mathrm{a}}$.-Teatros.

Es afán y propósito de esta Dirección General el llegar, en este orden de actividades a la creación de un Teatro Nacional, como existe en todos los países y cuya finalidad no es nunca competir con las empresas teatrales, sino suplirlas en aquello que ellas no pueden realizar, mediante la independencia económica que proporciona la ayuda del Estado.

Este teatro tendrá las siguientes finalidades: $1^{\text {a }}$ : Teatro Museo $2^{\mathrm{a}}$ : Teatro experiencia. $3^{\mathrm{a}}$ : Teatro religioso. $4^{\mathrm{a}}$. Teatro - escuela.

El apartado se completa con una serie de observaciones al respecto, que indicamos a continuación:

$2^{\text {a }}$. Música, con intención de crear una orquesta, «que resucitaría las obras de nuestros clásicos...»

$3^{\mathrm{a}}$. Monumentos, en defensa del Patrimonio Artístico.

$4^{\circ}$. Museos. La Dirección General, procurará realizar una política conjunta de Museos.

$5^{\text {a }}$. Excavaciones.

$6^{\circ}$. Enseñanzas artísticas.

$7^{\circ}$. Exposiciones de Bellas Artes.

Instrucciones para el mejor desempleo del personal eventual de acomodadores de este Teatro.

\section{Estructura del Teatro María Guerrero}

De la importancia del Teatro María Guerrero, precedente directo del Teatro Nacional, da idea el estudio, mecanografiado que, en cinco folios desarrolla un apartado: «Plantilla del personal de dicho Teatro con cargo a la Administración del mismo». Se publica en 1940 y se compone de los siguientes grupos: «Personal de acomodadores. Idem de limpieza. Idem de tocadores. Idem de obreros fijos y de temporada».

No faltan los puestos para el Jefe del Estado y el Gobierno. Se comprueban todos los detalles al respecto en un gremio tan elemental y humilde y podemos intuir la estricta obligación del Teatro María Guerrero en ese momento respecto a otras actividades, tal vez más solemnes.

Conviene recordar la jerarquía profesional: «Será su inmediato Jefe el Conserje, quien señalará el puesto que cada uno de aquellos ha de desempeñar». Todo ello se completa con diversos apartados, correspondientes a la condición del público, reflejando un complicadísimo esquema, con departamentos en nombres sustantivos, oficios, clases de trabajadores. Algo muy interesante, pero innecesario en estas líneas, salvo por su valor sociológico.

Con el apartado «Obreros fijos y de temporada» (en mayúsculas en el original) se remata el estudio, de importancia incuestionable para conocer la estructura de un teatro famoso, representado por un grupo de trabajadores humildes. 


\section{EI teatro renovado en la Posguerra. Advertencia previa. Clases de organismos próximos.}

Antes de ofrecer un panorama teatral mínimo del momento, conviene tener en cuenta un documento que creemos de poca difusión, pero que nos parece decisivo y que no debió funcionar como información popular. Se trata de una copia mecanografiada en tinta morada y con un título desnudo: Grupo Primero. Museos y Academias y Bibliotecas (con mayúsculas en el original). Se refiere a edificios señoriales y artísticos que hay que salvar y conservar después de la guerra civil. A pesar de que en el documento original están reflejados en mayúsculas, nuestra transcripción será en minúsculas.

Resulta sorprendente la nota autógrafa: «Nota: Los V (un subrayado muy personal); son edificios para los que se ha
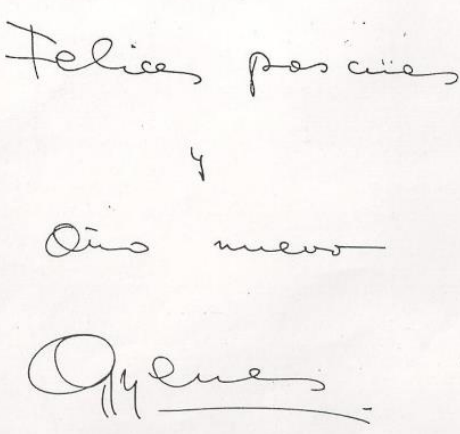

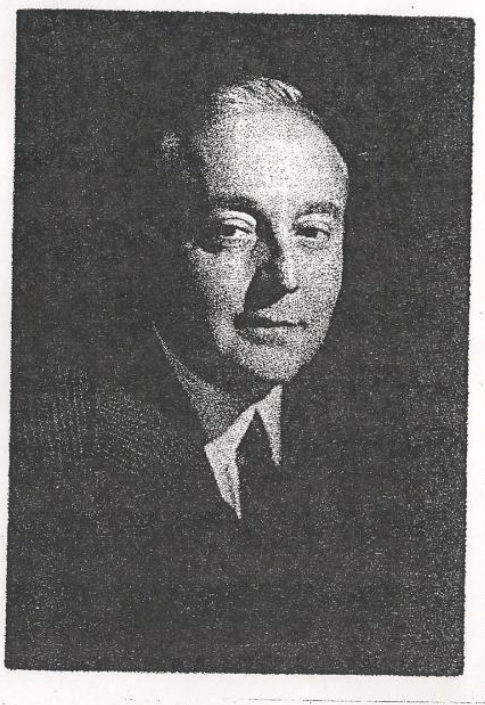
pedido guardia»:

Grupo primero. Museos, Academias y Bibliotecas. Como en todos los apartados siguientes, se indica el nombre del centro y la dirección en Madrid, con lo cual disponemos de una admirable y certera dirección, así como su cantidad en cada apartado: 36 edificios.

Grupo segundo. Conventos, iglesias y edificios públicos que sirven o han servido para museo y almacén de obras de arte.42 edificios.

Grupo tercero. Edificios que por su anterior condición o por su nuevo destino, tiene importancia considerable. 52 edificios.

Grupo cuarto. Edificios particulares que interesa conocer por lo que contuvieron y por el destino que han tenido. 43 edificios.

Grupo quinto. Domicilios cuyo estado interesa conocer y conservar tal y como los dejaron los rojos al ser ocupado Madrid. 41 edificios.

Grupo sexto. Locales que deben ser inspeccionados con carácter policial como medio de seguir el curso de los saqueos. Incluye casa de alhajas, de antigüedades, casas de libros y casas de muebles. Casas de compraventa.

En total, son aproximadamente doscientos cuarenta edificios señoriales, artísticos, reseñados, una relación de valor cultural y arquitectónico indiscutible.

\section{Preocupación por el estado del teatro}

No hay duda de que en el comienzo de la posguerra existe una honda preocupación por parte de un grupo de intelectuales, frecuentemente citados en estas líneas.

En un texto mecanografiado de Huberto leemos: 
La urgente necesidad de atajar la corriente de chavacanería (sic) y mal gusto, dueña de la escena española, que entregada sólo a la iniciativa comercial de las empresas, necesariamente atentas a sus intereses económicos, únicamente atienden al halago del público, sirviéndole aquellos que más puede responder a los bajos instintos de la masa hizo nacer el Teatro Nacional con sede en el local del María Guerrero, cuyo objeto es conservar, manteniéndola viva, la gloriosa tradición escénica que tan alto lustre ha dado en siglos anteriores a las letras españolas.

Y añade el texto: «Para ello es necesario ir educando el gusto del público por medio de representaciones depuradas al mismo tiempo que se forma sólidamente el criterio estético de un grupo de autores acostumbrándoles a los géneros nobles y las interpretaciones bellas». Líneas más adelante afirma:

Para lograr su cometido la Compañía del Teatro Nacional [que comienza el 27 de abril de 1940, en el María Guerrero, dirigido por Luis Escobar, Huberto Pérez de la Ossa y Claudio de la Torre, con La cena del rey Baltasar] atenderá en primer lugar a la reposición de las grandes joyas de nuestra dramática, estrenando por lo menos una obra clásica cada año y procurando rodear estas representaciones del mayor explendor (sic) posible, a fin de atraer con este incentivo al público totalmente desviado de los clásicos.

La experiencia les lleva incluso a proponer la creación de un reglamento para el mejor funcionamiento del teatro. Incluye siete largos artículos, subdivididos en apartados que completan el estudio. Aparecen como firmantes los intelectuales habituales del ambiente cultural. Y continúa el texto:

La experiencia de tres temporadas realizadas en Madrid y las excursiones efectuadas a provincias y al extranjero nos mueven a proponer a V. E. el siguiente reglamento para el mejor funcionamiento de dicho teatro. Son cuatro artículos que incluyen once cuartillas: Artículo $1^{\circ}$ : De la Dirección, administración y funcionamiento del Teatro Nacional. Artículo $2^{o}$. Para atender a sus elevados fines en cultura, el Teatro Nacional contará con cuatro objetivos repartidos en cuatro apartados, referidos al presupuesto del Estado, ingresos de venta de entradas, con legados y donativos y «cantidades del arriendo o cesión del local». Artículo $3^{\circ}$. Referido a los actores. Artículo $4^{\circ}$. «Personal administrativo». Artículo $5^{\circ}$. Personal técnico y subalterno. Artículo $6^{o}$. La Junta Ejecutiva. Artículo $7^{\circ}$. Domiciliación del Teatro: el Teatro María Guerrero, lo que explica el detallismo informativo.

No es necesario advertir que muchos de los artículos se ramifican en distintos aspectos. Es indudable, a pesar de carecer de fecha, que este borrador de Huberto es uno de los primeros planteamientos teatrales en el campo de la teoría dramática.

En 1937, en Zaragoza, (en bella edición numerada, con el número nº 79, dedicado a Huberto) se publica un folleto muy bien editado, de cuarenta páginas, con un mínimo estudio de Federico Blas Torralba Soriano, sobre Notas para la creación de un Teatro Nacional Español. El año es el II Año Triunfal. Lo introduce un prólogo de J. M. Castro y Calvo, Profesor de la Universidad de Zaragoza. La prolijidad informativa se completa con una excelente nota bibliográfica, con entradas en francés, inglés y alemán.

Son completas y abundantes las reflexiones para levantar el panorama teatral del momento de posguerra: artículos, libros conferencias, actos diversos, tratan de reanimar al mortecino ambiente teatral. Veamos algunos ejemplos. En el BOE del 8 de marzo de 1940 se publica un escrito que 
conservamos autógrafo. La obra, dividida en veinte capítulos, es un planteamiento perfecto de lo que debe ser el teatro como fenómeno cultural y humano. Es un estudio que podemos considerar modélico.

Aunque sólo mecanografiado, en estos mismos años, en la biblioteca de Huberto aparece un cuaderno que persigue, con mayor humildad los mismos objetivos, catorce páginas que incluyen catorce artículos. Surge con el deseo de plasmar la estructura del teatro del momento. Está surgiendo la Compañía del Teatro Nacional y su nuevo espíritu.

\section{La Comisaría nacional de Teatro}

Centrándonos en los papeles de Huberto observamos que el epígrafe anterior, «La Comisaría nacional de Teatro», es de los organismos más relevantes. Prueba de ello es que existen tres documentos informativos que, con variantes, desarrollan este mismo tema. Su cometido es claro:

La Comisaría tiene inmediatamente a su cargo la orientación, dirección y realidad diaria del Teatro Nacional. Así pues tiene a este respecto las funciones siguientes.

ARTICULO $1^{\circ}$.- A propuesta del Ministerio de Educación Nacional y dependiente de la Dirección General de Bellas Artes, se crea una Comisaría de Teatros, asistida de una Junta Nacional de Teatros en la que estarán representados los más altos valores teatrales en sus diferentes aspectos (Autores, Realizadores, Actores, Críticos y Empresarios.)

ARTICULO $2^{\circ}$. La Comisaría de Teatros Nacionales tiene la responsabilidad, la iniciativa y el desarrollo de la creación y el funcionamiento del Teatro Nacional y estará integrada por un Comisario y dos subcomisarios.

ARTÍCULO $3^{\circ}$ La Junta Nacional de Teatros conocerá los proyectos de la Comisaría y la asesorará con su superior consejo cuando por la misma fuerza reunida. Aprobará además el balance anual del Teatro Nacional.

ARTICULO $4^{\circ}$. El Teatro Nacional en su principio estará compuesto de los siguientes organismos:

A) Un Teatro Dramático Experimental, con domicilio en el Teatro María Guerrero para la representación escénica de un repertorio clásico y moderno en el que se ensayen nuevas formas de orientación, dirección y representación de las obras dramáticas nacionales y extranjeras seleccionadas por la comisaría.

B) Un Centro de Estudios Teatrales, de marcado carácter práctico, para cuantos elementos directores y auxiliare intervienen en las representaciones escénicas. Este Centro de Estudios crea becas que se proveerán anualmente.

C) Un Centro de Publicaciones Teatrales, para la difusión de la historia del Teatro, sus variadas influencias y las distintas orientaciones estéticas de la escena actual. Dicho Centro editará una revista de teatros como publicación regular.

D) Un cuerpo de Baile Español, con repertorio propio, de tipo exclusivamente nacional, cuya actuación en los teatros de España y del Extranjero deberá contribuir, por la calidad del espectáculo, a la mejor propaganda artística de nuestra España.

ARTICULO $5^{\circ}$. En el plazo máximo de un año, a contar de la fecha en que tome posesión del Teatro María Guerrero, la comisaría dará cuenta a la Junta Nacional de Teatros de regla del Teatro Nacional antes de su aprobación por la Dirección General de Bellas Artes.

El trabajo se completa con dos detallados esquemas autógrafos con el título «Dirección general de Bellas Artes», que arranca del concepto «Consejo directivo (o «Comisario directivo») y Junta Consultiva» hasta «Electricistas» en el campo final. Entre ambos extremos se reflejan todos los elementos de la compañía. 


\section{Otra versión de la Comisaría nacional de Teatro}

En otro borrador, transcrito mecanográficamente, aparece el apartado, extenso y muy interesante,

Comisaría Nacional de Teatro, en mayúsculas en el original. He ahí su contenido:

La componen un Comisario y dos subcomisarios, nombrados por el Ministerio de Educación Nacional a propuesta del Director General de Bellas Artes y el personal auxiliar que juzgue necesario.

La Comisaría tiene inmediatamente a su cargo la orientación, dirección y realidad diaria del Teatro Nacional. Así pues tiene a este respecto las funciones siguientes:

$1^{\circ}$. Decidirá las obras que hayan de ser representadas y orden en que haya de serlo.

$2^{\circ}$. Escogerá para cada obra un realizador.

$3^{\circ}$. Formará la compañía del Teatro Nacional con el elenco que juzgue oportuno.

$4^{\circ}$. Acordará la fecha de actuaciones, los lugares donde hayan de verificarse.

$5^{\circ}$. Vigilará la propaganda que de aquellas debe hacerse.

$6^{\circ}$. Acordará la forma de emplear la subvención concedida por el Ministerio y las cantidades que por otros conceptos perciba el Teatro Nacional.

Para mayor facilidad en la realización, la Comisaría designará de su seno un Delegado que será el ejecutor de sus designios. Podrá haber tantos delegados como funciones crea conveniente haber de desempeñar. (Así, un Delegado para la Compañía Nacional, uno para las Ediciones, otro para la Enseñanza o la escuela, etc.).

La Dirección de Bellas Artes (corregido sobre «La Comisaría») convocará las reuniones de la Junta Nacional de Teatros y la Comisaría (corregido, incorporado), informará, a la misma de sus proyectos y de la marcha general del Teatro. Igualmente deberá presentar a la Junta una me memoria sobre la marcha económica del mismo.

La estructura teatral incluye otros apartados y funciones muy interesantes que reproducimos a continuación.

\section{REALIZADOR TÉCNICO}

Comienza ahora la reproducción literal de los distintos elementos, humanos y burocráticos. La reproducción es prolija, pero detallada. De esta forma es más fácil captar el espíritu burocrático que late en todas estas disposiciones, rigurosamente elaborado.

Es el Dictador de cada obra.

Lo elige la Comisaría que podría exigirle cuantos detalles juzgue oportunos sobre la obra que se le ha encomendado, así como un presupuesto aproximado del montaje.

El Realizador elige los papeles, ensaya a los actores, monta las luces, elige quién ha de dibujar los decorados y figurines y, en general, dispone cuanto sea preciso para asegurar el éxito de la obra que le ha sido encomendada. Todas las personas que componen el Teatro Nacional se pondrán con todo entusiasmo a las órdenes del realizador al que ayudarán con su máximo esfuerzo.

Una vez elegido el Realizador y aprobado su presupuesto de Montaje, la Comisaría dejará al Realizador una amplia libertad en cuanto a la forma de realizar su trabajo. Sin embargo se reserva una censura artística, política y moral que pueda llegar en algún caso a prohibir que la obra sea representada o a sustituir al realizado. El Realizador tiene, como única retribución de su trabajo. El 5\% del beneficio de la obra.

\section{ACTORES}

Apartado $1^{\circ}$ Contrato y categoría

A.- Los actores serán contratados por la Comisaría Nacional de Teatros. Firmarán el contrato por un año que no podrá ser rescindido sino de acuerdo con la parte contratante.

$B$. - Caso de ser firmado nuevo contrato, éste lo será un mes antes de extinguirse el contrato anterior.

C.- Habrá una sola categoría de actores, significando esto que se considera a cualquier actor del Teatro

Nacional como de máxima categoría, represente el papel que represente. 
D.- Caso de infringir un actor el presente reglamento le podrá ser rescindido el contrato sin derecho a ulterior reclamación.

\section{Apartado $2^{\circ}$ Sueldo y Beneficio}

A.- Los actores tendrán un sueldo único de 30 pesetas diarias y lo percibirán durante todo el año, aun cuando la compañía no trabaje.

$B$ - En el caso de salir la compañía de su domicilio de Madrid, los actores percibirán dietas de viaje y desplazamiento que se fijarán oportunamente.

$C$ - Los actores percibirán además un tanto por ciento, en el beneficio de cada obra. Este será: 172 por ciento a partir de las 1.500 pesetas de recaudación en el periodo de amortización, y de $1 \frac{112}{2} \%$ a partir de las 1000 pesetas de recaudación en el Beneficio.

\section{Apartado $3^{\circ}$. Deberes y derechos}

A.-Los actores deberán asistir puntualmente a las horas de ensayo y encontrarse en el

Teatro media hora antes de comenzar la representación. En la hora en punto en que la representación haya sido anunciada los actores deben encontrarse en el escenario, vestidos y maquillados.

$B$ - No podrán negarse a representar determinado papel.

$C$ - No podrán representar fuera del Teatro Nacional ni tomar parte en recitales o funciones benéficas sin permiso de la Comisaría Nacional.

$D$ - Los actores tienen derecho a conocer su papel quince días antes de la representación cuando se trata de un estreno y ocho días antes cuando se trate de una reposición.

De los artículos citados surge una evidencia, la organización de los teatros y concretamente de los actores españoles responde a una clara exigencia: dotar a los actores de una infraestructura envidiable. Se exige profesionalidad, preparación y entrega, pero se corresponde con lograr una vida llena de ventajas. No era ése, en efecto, el ritmo de los españoles del momento.

\section{REGIDOR GENERAL}

Es la cabeza de la compañía y el intermediario posible entre la Comisaría y los actores o el Realizador y los actores.

Cuidará de la disciplina de la compañía y resolverá los pequeños pleitos internos que o tengan por qué llegar a la Comisaría.

Tiene a su cargo inmediato a la encargada de guardarropa y al encargado de la peluquería. De él dependen también el Jefe de servicios y todo el personal de este, salvo para aquello puramente técnico para lo cual dependen del Jefe Técnico.

Es el encargado de la tablilla de avisos.

\section{REGIDOR TÉCNICO}

Es el encargado de la luminotecnia y de la construcción de Decorados y accesorios. Tiene a sus órdenes al Jefe de Servicios para cuanto atañe a su cometido.

Ayudará a los pintores, a quienes se hayan encargado de decorados, en la cuestión de planos a escala y media, ya que el Teatro Nacional se dirigirá con cierta frecuencia a pintores por solo hecho de tener talento, aun cuando sea la obra que se les encomiende, sus primeras armas en escenografía.

\section{SECRETARÍA}

Está compuesta por: un Secretario, un Encargado de Propaganda, una Taquimecanógrafa, un Contable, un ordenanza.

La Secretaría lleva todos los asuntos del Teatro de fuera de la escena. Es decir: Propaganda, Contabilidad, arreglo de tournées, abonos, correspondencia, archivo, etc.

La Administración corresponde a un funcionario nombrado por el Ministerio. 


\section{MECÁNICA DE FUNCIONAMIENTO}

Para proceder al montaje de una obra elegida por la Comisaría, ésta escoge un Realizador, el cual deberá, si no es lo suficientemente conocido, para poder confiar en él a ojos cerrados, presentar un proyecto de realización como en todo caso deberá presentar un presupuesto aproximado.

Una vez aprobado este y el presupuesto de realización, se fija por la comisaría el momento de comenzar los ensayos, teniendo en cuenta que estos deben empezar cuanto menos quince días antes del estreno.

Desde el momento de comenzar los ensayos, el Realizador dispone del teatro, del personal y de la compañía durante tres horas diarias, por la tarde. Este tiempo puede acortarlo si lo juzga oportuno. Si cree que falta ensayo para la fecha del estreno podrá o pedir ensayos suplementarios, pero el conceder esto o no es potestativo de la Comisaría. El Regidor General y el Regidor Técnico estarán junto a él para cuando precise durante el ensayo y el Realizador se entenderá con ellos y con los actores directamente.

La Comisaría decide la fecha del estreno así como la duración de la obra en el cartel. Igualmente podrá la Comisaría reponerla cuando lo juzgue oportuno o alternar varias obras.

La compañía representará todos los días una vez, salvo los jueves, sábados y domingos en que se podrán dar dos representaciones».

Son muestras de investigación diversas, pero idénticas en su objetivo. Como lo es otro documento autógrafo de Huberto, con el que cierra el escrito y en el que anuncia como objetivo:

Para cumplir esta misión formativa y educadora en orden a la cultura teatral de nuestro pueblo, dispongo:

Si el teatro como medio de educación del pueblo, vehículo difusor de ideas, y medio de llevar un sentido de estética a las capas sociales más diversas, es en todos los paisajes cultos objeto de atención preferente por parte del estado y aun los que juzgan rota toda la tradición y sin valor alguno el legado clásico de los siglos, se esfuerzan por satisfacer la necesidad estética en ficción que los hombres han sentido eternamente. Mas ha de ser real para España, cuyo teatro clásico tiene sitio de honor entre los primeros del mundo.

No puede dejarse pues a la iniciativa del teatro universal. Abrir el horizonte a las nuevas tendencias. Servir de acicate y estímulo a los ingenios actuales que sin la angostura de una empresa podrán dar plenamente la medida de su valer». [Hay ocho líneas tachadas].

Dentro del cuadernillo, se conserva una página con nombres representativos al respecto, que reflejamos a continuación:

Campaña del Teatro Nacional

(2) Colaboradores.

(1) Don Antonio Obregón. «Arriba»

(1) Don Nicolás González Ruiz. «Ya»

(2) Don Luis Araújo Costa.

Don José Montero Alonso.

Lo firma Huberto P. de la Ossa. Departamento de Cinematografía. Medinaceli, 4.

Hay en estas disposiciones todo un corpus de comportamiento humano, de condición ética en muchas observaciones. De cumplirse, ningún actor podría quejarse de las disposiciones legales.

Para mejor comprobación y mayor exactitud reflejamos el suelto del diario $Y a$ de 12 de Noviembre de 1939, Constitución del Consejo Nacional del Teatro: 
En la Dirección General de Bellas Artes y bajo la presidencia del marqués de Lozoya, se reúne el Consejo Nacional del Teatro, con asistencia de su presidente don Eduardo Marquina, los consejeros don Manuel Machado, don Pedro Mourlane, don Melchor Fernández Almagro, señora marquesa de Laula, doña María Guerrero de Díaz de Mendoza, don Luis Araujo Costa, don José Juan Cadenas, don Federico Moreno Torroba, el Comisario nacional de Teatros, don Luis E., y los subcomisarios don Claudio de la Torres y don Huberto Pérez de la Ossa.

En el mismo apartado se da la lista de la Junta Nacional de Teatros, y se aportan otros nombres: José María Pemán, J. Ignacio Luca de Tena, Juan Mestres y Calvet, Pedro Pruna, Marqués de Bolarque, J. Álvarez Quintero, Ricardo Calvo.Y, escritos a mano y con lapicero, María Guerrero de Díaz de Mendoza, Dámaso Alonso y Manuel Abril. Todo esto figura en la página siguiente bajo el epígrafe de Junta Nacional de Teatros. Una vez más coinciden los miembros consagrados de la cultura española, tantas veces repetidos en los papeles de Huberto. Sin olvidar el nombre de Felipe Lluch, tipo un poco marginal, pero decisivo en el mundo del teatro de este momento.

\section{Huberto, secretario de la Real Escuela Superior de Arte Dramático de Madrid}

Comprobamos las experiencias didácticas y profesionales que lleva a cabo Huberto al menos, desde 1952, como se observa en distintos documentos escritos, vitales y académicos. Podemos hacer un breve recorrido por ellos.

Antes de 1956, el archivo de Huberto guarda un documento excelente sobre la Escuela Superior de Arte Dramático de Madrid: «Debe tener como función primordial el mantener viva la tradición teatral española, fomentando e incrementando el amor al teatro en las nuevas generaciones de escritores y artistas».

A ellos se une una larga relación de observaciones respecto a la Escuela, dirigidas a un ILMO.SEÑOR, a quien el autor de estas reflexiones con respeto se dirige:

[...] para presentarle compilada y ordenadamente un resumen de las aspiraciones y propósitos que me guían en la labor que desde la dirección de la misma me he propuesto realizar y que en alguna ocasión he tenido el honor de exponerlo, en parte, de palabra.

Todo ello da lugar a una entrega espléndida, centrada en el descrédito que han sufrido las viejas secciones de Declamación de los Conservatorios. Se insiste en que sigue el anquilosamiento y se respetan los métodos antiguos de enseñanza. Y no falta un cierto divinismo al referirse al idioma:

El idioma, don supremo que Dios otorgó al hombre, al insuflarle su divino aliento, coronación suprema de la Creación, vehículo eterno del espíritu para todas las sublimaciones, como todas las cosas vivas, está en perpetua evolución; pero esta evolución, que puede ir por un cauce de perfección y de belleza, puede caer a veces en derrumbaderos y hasta en lodazales y simas de negrura donde corrompa y destruya [...]

Y es el de revalorizar la declamación del verso, recordando el brillante verso del Teatro del Siglo de Oro [...] los alumnos han de salir de la Escuela diciendo perfectamente los versos, declamando de un modo moderno. 
Igualmente, la Escuela está perfectamente preparada, pero el alumno tiene que tomar conciencia de ello. No falta la preocupación de Danza, «cuya definitiva concreción es cada día más necesaria [...] Urge, pues, la creación de cátedras de Danza Clásica y de Ballet moderno». Es necesario conseguir para el teatro «que se rijan normas parecidas a las de Radio Nacional de España, tanto en lo que se refiere a la recluta de sus locutores como en los actores para su Teatro radiofónico».

El final es esperanzador: «La elevación de nivel cultural y artístico de nuestros alumnos diplomados, es lo único que puede levantar el prestigio de nuestra Real Escuela de Arte Dramático en un futuro inmediato».

A partir de estos presupuestos, disponemos de todas las reflexiones, integrando diez intensos y jugosos folios, que encierran temas diversos. El nuevo plan podría fundarse en diversas bases, en primer lugar el de los alumnos, que se desglosa en múltiples apartados académicos, incluidos en tres cursos. El objetivo es claro. «He aquí algunas bases en que podría fundarse el nuevo plan». Es un planteamiento didáctico que aquí eludimos.

\section{La cima académica}

El 23 de abril de 1959 Huberto Pérez de la Ossa recibe el nombramiento de «Secretario de la Escuela Superior de Arte Dramático de Madrid, con la gratificación anual de cinco mil pesetas para gastos de representación»».

Firma el nombramiento el Sr. Ministro de Educación Nacional. Se confirma así el denodado

esfuerzo de nuestro autor en pos de los problemas del teatro. Ahora ejercerá su afición desde el punto de vista de la enseñanza.

Por la documentación de la que disponemos (textos, cuadros de la Escuela, borradores, etc.) Huberto Pérez de la Ossa se hace cargo de la Cátedra de Dirección de Escena, como se comprueba en actas autógrafas con la calificación, siempre generosa, de los alumnos, casi exclusivamente femenina. Es un digno final profesional para tanta obra conservada.

Poco hay que decir, salvo que la figura de Huberto Pérez de la Ossa, merecía mejor tratamiento. Que estas líneas sirvan humildemente para recuperar su figura, guardada entre el polvo de los recuerdos y entre las estanterías de las librerías de lance.

Querido José Enrique:

Supongo que habrás quedado cansado de mis palabras y del recuerdo de Huberto por su sabiduría y actitud conservadora. Quizás ha sido excesivo mi empeño, demasiado pretencioso, pero tanto Huberto como tú, sobre todo tú...os lo merecéis.

Recibe un fuerte abrazo y que disfrutes de una feliz y fructífera jubilación. 